\title{
Axonally Derived Neuregulin-1 Is Required for Remyelination and Regeneration after Nerve Injury in Adulthood
}

\author{
Florence R. Fricker, ${ }^{1}$ Natalia Lago, ${ }^{1}$ Sharmili Balarajah, ${ }^{1}$ Christoforos Tsantoulas, ${ }^{1}$ Shamil Tanna, ${ }^{1}$ Ning Zhu, ${ }^{1}$ \\ Samaher K. Fageiry, ${ }^{1}$ Mark Jenkins, ${ }^{1}$ Alistair N. Garratt, ${ }^{2,3}$ Carmen Birchmeier, ${ }^{2,3}$ and David L. H. Bennett ${ }^{1}$ \\ ${ }^{1}$ Wolfson Centre for Age-Related Diseases, King's College London, Guy's Campus, London SE1 1UL, United Kingdom, ${ }^{2}$ Max Delbrueck Center for Molecular \\ Medicine, 13092 Berlin, Germany, and ${ }^{3}$ Charité Universitätsmedizin Berlin, 10117 Berlin, Germany
}

Neuregulin-1 (NRG1) plays a crucial role in axoglial signaling during the development of the peripheral nervous system, but its importance in adulthood after peripheral nerve injury remains unclear. We used single-neuron labeling with inducible Cre-mediated knock-out animals, which enabled visualization of a subset of adult myelinated sensory and motoneurons neurons in which Nrg1 was inducibly mutated by tamoxifen treatment. In uninjured mice, NRG1-deficient axons and the associated myelin sheath were normal, and the neuromuscular junction demonstrated normal apposition of presynaptic and postsynaptic components. After sciatic nerve crush, NRG1 ablation resulted in severe defects in remyelination: axons were either hypomyelinated or had no myelin sheath. NRG1-deficient axons were also found to regenerate at a slower rate. After nerve injury, the neuromuscular junction was reinnervated, but excess terminal sprouting was observed. Juxtacrine Neuregulin-1 signaling is therefore dispensable for maintenance of the myelin sheath in adult animals but has a key role in reparative processes after nerve injury.

\section{Introduction}

Neuregulin-1 (NRG1) has a key role in the development of the peripheral nervous system. Alternative splicing and differential promoter usage gives rise to at least 15 different NRG1 isoforms that demonstrate different spatiotemporal patterns of expression (Meyer et al., 1997; Falls, 2003; Mei and Xiong, 2008). All isoforms possess an epidermal growth factor (EGF)-like signaling domain, which is essential for mediating biological activity, and can be classified into subgroups according to the structure of their $\mathrm{N}$ termini. Isoforms containing Ig-like domain (types I, II, and IV) can be either directly secreted or released as soluble proteins from the cell surface after proteolytic cleavage. Isoforms possessing a cysteine-rich domain (type III isoforms) have two transmembrane domains, require proteolytic cleavage by BACE1 ( $\beta$-site APP-cleaving enzyme 1$)$ for full activity, and signal in a juxtacrine manner (Hu et al., 2006; Willem et al., 2006).

During development, axonally derived NRG1 signals via ErbB2 and ErbB3 receptor heteromers expressed on Schwann cells and regulates multiple aspects of Schwann cell differentiation, including the survival of Schwann cell precursors, Schwann cell proliferation, motility, axon ensheathment, and myelination

Received May 20, 2010; revised Nov. 5, 2010; accepted Dec. 28, 2010.

F.R.F. is a Biotechnology and Biological Sciences Research Council Collaborative Awards in Science and Engineering PhD student funded in part by Acorda Therapeutics Inc. D.L.H.B. is a Wellcome Intermediate Clinical Scientist (Grant 077074/z/05/z). C.T. is a PhD student of the Wellcome Trust-funded London Pain Consortium. A.N.G. and C.B. acknowledge the support of the German Science Foundation (Sonderforschungsbereich 665).

Correspondence should be addressed to Dr. David L. H. Bennett, Wolfson Centre for Age-Related Diseases, King's College London, Guy's Campus, London SE1 1UL, UK. E mail: david.bennett@kcl.ac.uk.

DOI:10.1523/JNEUROSCI.2568-10.2011

Copyright $\odot 2011$ the authors $\quad 0270-6474 / 11 / 313225-09 \$ 15.00 / 0$
(Meyer and Birchmeier, 1995; Riethmacher et al., 1997; Morris et al., 1999; Woldeyesus et al., 1999; Garratt et al., 2000; Chen et al., 2003; Michailov et al., 2004; Taveggia et al., 2005; Fricker et al., 2009). Early in vitro studies suggested that NRG1 may also have a role in acetylcholine receptor clustering during development of the neuromuscular junction (NMJ) (Falls et al., 1993). More recent genetic approaches have however indicated that NRG1ErbB signaling is dispensable for postsynaptic differentiation at the NMJ (Escher et al., 2005; Jaworski and Burden, 2006). NRG1 has also been shown to modulate the behavior of terminal Schwann cells at the NMJ because it increases survival of these cells after postnatal denervation (Trachtenberg and Thompson, 1996) and promotes process extension (Hayworth et al., 2006).

Because of the key developmental role of NRG1 in Schwann cell development, it has been challenging to study the function of this molecule in adulthood in relation to both maintenance of myelin and the response to nerve injury. The peripheral nervous system shows significant ability for repair after either traumatic or immune-mediated injury (Chen et al., 2007). The coordinated signaling between regenerating axons and Schwann cells is likely to be critical for both axon remyelination and regeneration; given its developmental functions, NRG1 is an attractive target for fulfilling such a role. To investigate the role of axon-derived NRG1 signaling, we have used "SLICK" (single-neuron labeling with inducible Cre-mediated knock-out) mice (Young et al., 2008) in which the enzyme Cre recombinase is inducibly activated, resulting in NRG1 ablation in a subset of myelinated motor and sensory axons that also express yellow fluorescent protein (YFP). We demonstrate that juxtacrine NRG1 signaling is not required for maintenance of the myelin sheath and NMJ nor for axon integ- 
rity, but it is essential for multiple aspects of the reparative response after nerve injury, including remyelination, axon regeneration, and normal reinnervation of the NMJ.

\section{Materials and Methods}

Animals

All work performed conformed to United Kingdom Home Office legislation (Scientific Procedures Act 1986). SLICK-A Cre; NRG-1 $1^{f l f l}$ were bred by crossing SLICK-A Cre mice (JAX mice 007606; The Jackson Laboratory) with $N R G-1^{f l f l}$ mice; both colonies were on a C57BL/6 background. The generation and genotyping of mutant mice with floxed alleles of $\mathrm{Nrg} 1\left(\mathrm{Nrg}^{\mathrm{fff}}\right)$ and SLICK-A Cre mice has been described previously (Yang et al., 2001; Brinkmann et al., 2008; Young et al., 2008; Fricker et al., 2009). Genotyping of SLICK-A Cre; NRG- $1^{f l / f l}$ mice was performed by using PCR of genomic DNA to detect the presence of the loxP sites. The primers used were as follows: 5'-TTTGGTGGACTGGGTTTCTC-3' and $5^{\prime}$-CTGACTGGCCTTTCTTCCAG-3' (performed as follows; heating at $94^{\circ} \mathrm{C}$ for $2 \mathrm{~min}$, 34 cycles of $94^{\circ} \mathrm{C}$ for $30 \mathrm{~s}, 60^{\circ} \mathrm{C}$ for $30 \mathrm{~s}$, and $72^{\circ} \mathrm{C}$ for $50 \mathrm{~s}$, followed by a final extension at $72^{\circ} \mathrm{C}$ for 8 $\mathrm{min})$. To detect the SLICK-A Cre construct, ear punches were examined for YFP fluorescence under a fluorescent microscope.

In SLICK-A Cre mice, a tamoxifen-inducible form of Cre recombinase is simultaneously expressed with YFP in the same cells. Expression is driven by two copies of the Thyl promoter and is seen in a small population of motor axons and large DRG cells. YFP expression is constitutive, whereas Cre activity is drug inducible. Tenweek-old SLICK-A Cre; NRG-1 $1^{f l / f l}$ mice were dosed by oral gavage with $0.25 \mathrm{mg} / \mathrm{g}$ body weight with tamoxifen (Sigma T5648) in corn oil, prepared as described previously (Young et al., 2008) or with corn-oil-alone vehicle for 5 consecutive days. After dosing, animals were left for 4 weeks before surgery. In each experiment, SLICK-A Cre; NRG- $1^{f l f l}$ tamoxifentreated animals were compared with SLICK-A Cre; NRG-1 $1^{\text {fl/fl }}$ vehicletreated animals. As an additional control, comparison was also made with SLICK-A Cre; NRG-1 $1^{+/+}$tamoxifen-treated controls. We included equal numbers of animals of each gender in experimental groups whenever possible.

\section{Surgery}

One month after tamoxifen/vehicle treatment, the right sciatic nerve was exposed and crushed two times, in two different directions $30 \mathrm{~s}$ each time, with fine forceps. The lesion site was kept a constant $43 \mathrm{~mm}$ from the tip of the third digit, by laying a measured thread over the anatomical trajectory of the sciatic nerve. The crush site was labeled with lamp black. The wound was closed with 5-0 sutures and disinfected. A schematic diagram of the sciatic nerve crush model is shown in Figure 1. The sciatic and tibial nerves and the gastrocnemius muscle were harvested at $10 \mathrm{~d}$, $14 \mathrm{~d}$, and 2 months after crush.

In situ hybridization combined with fluorescence histochemistry Ablation of NRG1 at the mRNA level was demonstrated using in situ hybridization (ISH) as described previously (Fricker et al., 2009). After prehybridization treatments (acetylation, delipidation, dehydration), sections were incubated overnight at $37^{\circ} \mathrm{C}$ with radioactively ( $\left[{ }^{35} \mathrm{~S}\right]$ dATP; PerkinElmer Life and Analytical Sciences) end-labeled (terminal deoxynucleotidyl transferase; Promega) probe in hybridization buffer. The probe sequence was CTGGTGATCGTTGCCAAAACTACGTAATGGCCAGC (Sigma-Aldrich), directed against the $\beta$ EGF domain of mouse NRG1 mRNA (NM_178591), and its specificity has been shown previously. Solutions and materials used during tissue preparation and prehybridization steps were RNase free or DEPC treated. The next day, slides were washed in SSC solutions with increasing stringencies (final wash, $0.2 \times \mathrm{SSC}$ at $50^{\circ} \mathrm{C}$ ), dehydrated, air dried, dipped in LM1 autoradiographic emulsion (GE Healthcare), and exposed for 3 weeks before development. Slides were mounted with Vectashield (Vector Laboratories), and signal was visualized on a Carl Zeiss microscope fitted with an epifluorescence polarized light block. For quantification of ISH signal in motoneurons, YFP-positive cells exhibiting grain density twice background levels were counted as exhibiting a positive hybridization signal. All analyses were performed with the operator blinded to group.

\section{Histology}

Immunofluorescence microscopy. Animals were deeply anesthetized with pentobarbitone and transcardially perfused with $5 \mathrm{ml}$ of saline, followed by $25 \mathrm{ml}$ of paraformaldehyde ( $4 \%$ in $0.1 \mathrm{M}$ phosphate buffer). L4 DRGs and gastrocnemius muscle were postfixed in paraformaldehyde ( $4 \%$ in $0.1 \mathrm{M}$ phosphate buffer) for $2 \mathrm{~h}$ and then transferred to $20 \%$ sucrose overnight $\left(4^{\circ} \mathrm{C}\right)$. Tissue was then mounted in OCT embedding compound on dry ice and stored at $-80^{\circ} \mathrm{C}$. Transverse sections of the DRGs were cut at $10 \mu \mathrm{m}$ on a cryostat onto SuperFrost Ultra Plus slides. Longitudinal sections of gastrocnemius were cut on a freezing microtome at $100 \mu \mathrm{m}$ into a 24 well plate and stored in PBS containing $0.1 \%$ sodium azide. Whole tibial nerves were mounted on SuperFrost Ultra Plus slides in Vectashield mounting medium (Vector Laboratories).

Antibodies. DRG cell profiles were visualized by staining for either anti- $\beta$-galactosidase (5 Prime $\rightarrow 3$ Prime), IB4 isolectin $\mathrm{B}_{4}$ biotin conjugate $(10 \mu \mathrm{g} / \mathrm{ml}$; L2140; Sigma-Aldrich), polyclonal sheep calcitonin gene-related peptide (CGRP) (1:800; CA1137; Biomol), or monoclonal mouse anti-neurofilament 200 clone N52 (1:500; N0142; Sigma). Secondary antibodies used were as follows: ExtrAvidin-FITC (1:500; E2761; Sigma), anti-sheep cyanine 3 (1:400; 713-166-147; Stratech), and donkey anti-mouse FITC (1:200; 715-095-150; Stratech). For analysis, YFP signal was enhanced using either rabbit anti-green fluorescent protein (GFP) (1:1000; A11122; Invitrogen) or chicken anti-GFP (1:1000; 13970-100; Abcam) and the secondary antibodies Alexa Fluor 488 goat anti-rabbit (1:1000; A11070; Invitrogen) and Alexa Fluor 488 goat anti-chicken (1: 1000; A11039; Invitrogen). Neuromuscular junctions were visualized using $\alpha$-bungarotoxin Alexa Fluor 647 conjugate (1:1000; B35450; Invitrogen) or $\alpha$-bungarotoxin tetramethylrhodamine conjugate (1:1000; T1175; Invitro- 

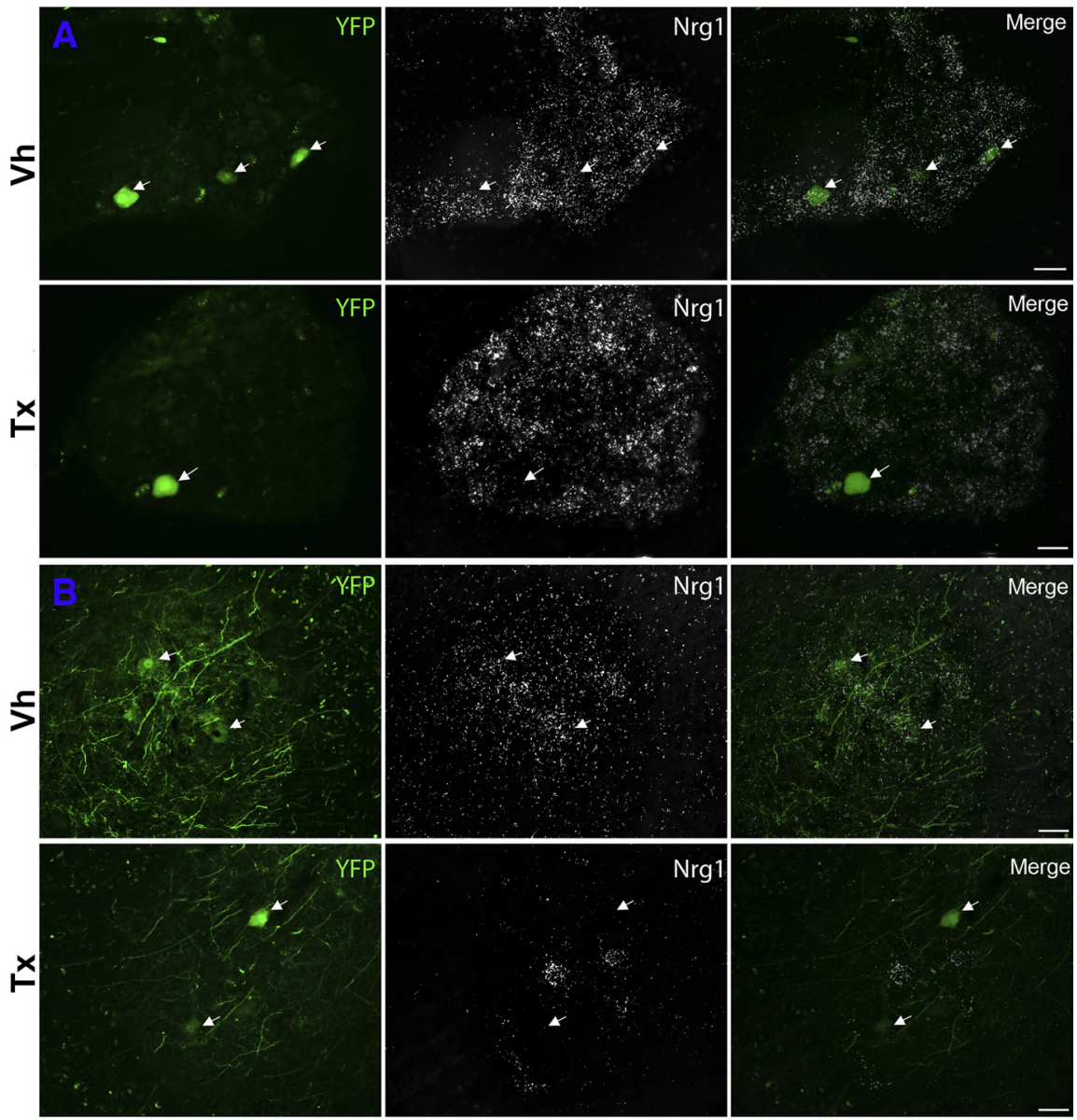

Figure 2. NRG1 ablation is specific to YFP-expressing motoneurons and large DRG cells after tamoxifen treatment. $A$, In situ hybridization images using a probe directed against the $\beta$ EGF domain of NRG1 in L4 DRG. $\boldsymbol{B}$, In situ hybridization images of the ventral horn of the spinal cord at the level of the lumbar enlargement. Images are of tamoxifen-dosed and vehicle-dosed SLICK-A Cre; NRG- $-^{f / f l}$ animals (conditional NRG1 mutant). A population of motoneurons within the ventral horn of the spinal cord and a small population of DRG cells express YFP (arrows). In tamoxifen-dosed animals, NRG1 expression is absent in these cells (whereas in YFP-negative cells, expression of NRG1 is maintained). Vh, Vehicle; Tx, tamoxifen. Scale bars, $50 \mu \mathrm{m}$.

gen). Terminal Schwann cells were visualized with S100 staining using rabbit S100 polyclonal antibody (1:400; Z0311; Dako) and secondary Alexa Fluor 546 goat anti-rabbit (1:1000; A11035; Invitrogen). Axonal myelin was visualized using rat monoclonal to myelin basic protein (1:200; 7349-2; Abcam) and secondary Alexa Fluor 546 goat anti-rat (1:1000; A11051; Invitrogen). Incubation of primary antibodies was overnight and was preceded by incubation with normal donkey serum (S30, 1:10, 30 min; Millipore Bioscience Research Reagents). All reagents were diluted in PBS containing 0.2\% Triton $\mathrm{X}-100$ and $0.1 \%$ sodium azide.

Immunofluorescence was visualized under a Carl Zeiss Imager.Z1 microscope or a confocal Carl Zeiss LSM 700 laser scanning microscope. Photographs were taken using the Axio Cam and AxioVision LE release 4.2 or the LSM Image Browser software for image analysis. Three intact representative muscle sections were selected from the central third of the gastrocnemius muscle and analyzed. Counts were taken of total and YFP axon innervated neuromuscular junctions live on a Carl Zeiss Imager.Z1 microscope, and the experimenter was blinded to the animal group. Terminal neuromuscular junction sprouts were analyzed from confocal photomicrographs, 50 images were taken from one section per animal, and the sprouts were measured using NIH Image J software. The operator was also blinded to each group for this analysis.

\section{Immunoelectron microscopy}

A preembedding immunoelectron microscopy method was applied. Animals were deeply anesthetized with pentobarbitone and transcardially perfused with $5 \mathrm{ml}$ of saline, followed by $25 \mathrm{ml}$ of $4 \%$ paraformaldehyde in $0.1 \mathrm{~m}$ phosphate buffer. The sciatic nerve was dissected and pinned straight on a gelatincoated dish. Nerves were postfixed in $4 \%$ paraformaldehyde, $2 \%$ glutaraldehyde, and $0.1 \mathrm{M}$ phosphate buffer at $4^{\circ} \mathrm{C}$ overnight before being embedded in $10 \%$ gelatin (48724; Sigma); once the gelatin had set, blocks containing each nerve were cut and stored in $4 \%$ paraformaldehyde at $4^{\circ} \mathrm{C}$ overnight, after which the paraformaldehyde was replaced with $\mathrm{PBS} / 0.1 \%$ azide. Transverse sections of sciatic nerves were cut using a vibratome (Leica VT 1000 S) at $100 \mu \mathrm{m}$. Sections were stored in PBS $/ 0.1 \%$ azide at $4^{\circ} \mathrm{C}$.

Sections from $2 \mathrm{~mm}$ distal to the crush site were taken for immunoelectron microscopy. For YFP staining, gelatin sections of sciatic nerve were washed in $\mathrm{PBS} / 0.1 \%$ bovine serum albumin (BSA) (A9576; Sigma), incubated for $30 \mathrm{~min}$ with $10 \mathrm{mg} / \mathrm{ml} \mathrm{NaBH}_{4}$, and then washed again in $\mathrm{PBS} / 0.1 \% \mathrm{BSA}$ before incubation for 20 min with $0.3 \% \mathrm{H}_{2} \mathrm{O}_{2}$ in PBS. Sections were then blocked with normal donkey serum (S30, 1:10, 30 min; Millipore Bioscience Research Reagents) before incubating overnight with rabbit anti-GFP in PBS (1:1000; A11122; Invitrogen). Sections were washed and then incubated with anti-rabbit biotin in PBS (1:400, 3 h; BA1000; Vector Laboratories), and sections were washed before incubation for 30 min with Vectastain ABC kit (PK-6100; Vector Laboratories). Sections were washed, and $\mathrm{DAB}$ staining was performed according to the instructions of the manufacturer with a development time of $10 \mathrm{~min}$ (DAB Peroxidase Substrate kit, SK-4100; Vector Laboratories). Sections were stored in $0.1 \mathrm{M}$ phosphate buffer at $4^{\circ} \mathrm{C}$.

Stained sections were osmicated, dehydrated, and embedded in epoxy resin (TAAB Embedding Materials). Sections of $1 \mu \mathrm{m}$ thickness were cut on a microtome and stained with toluidine blue before being examined on a light microscope. Ultrathin sections were cut on an ultramicrotome and stained with lead uranyl acetate by the Centre for Ultrastructural Imaging, Kings College London. Sections were mounted on unsupported 100 mesh grids, and sections were visualized on a Hitachi $\mathrm{H} 7600$ transmission electron microscope.

For analysis, photographs of positively stained axons only from each animal were taken at a magnification of $15,000 \times$. All positively stained axons in the field of view on one mesh grid were photographed and analyzed, and at least 125 axons were analyzed per experimental group. Total counts of myelinated axons were performed using a semithin crosssection of the whole sciatic nerve at the same level. G-ratios of positively stained axons were measured per animal using AxioVision LE release 4.2 software.

\section{Statistical analysis}

Differences between SLICK-A Cre; NRG- $1^{f l / f l}$ tamoxifen-treated animals and vehicle-treated controls were determined using the Student's $t$ test for comparison of two groups, or one-way ANOVA or two-way ANOVA using the Tukey's post hoc test for more than two groups. Results are reported as mean values \pm SEM. Cumulative frequency of axonal sprout length were compared statistically using the Kolmogorov-Smirnov test.

\section{Results}

Juxtacrine NRG1 signaling is not required for maintenance of the myelin sheath in adult animals

SLICK-A mice coexpress a tamoxifen-inducible form of Cre recombinase and YFP in a subpopulation of motor and sensory 
neurons (Young et al., 2008). In the SLICK-A line, the proportion of motoneurons that express YFP depends on the spinal level and muscle examined (Young et al., 2008). At the level of the lumbar spinal cord, $33.14 \pm 2.00 \%(n=$ 4) of motoneurons (identified by choline acetyltransferase immunostaining) expressed YFP (supplemental Fig. 1, available at www.jneurosci.org as supplemental material). In the SLICK-A mouse, a small percentage $(1.7 \pm 0.3 \%)$ of DRG cell profiles were also YFP positive, and all of these DRG cells were also immunostained for phosphorylated neurofilament heavy chain (a marker for DRG cells with large-diameter myelinated axons) (supplemental Fig. 2, available at www.jneurosci.org as supplemental material) but did not express CGRP or bind IB4 (markers of small-diameter DRG cells with unmyelinated axons; data not shown).

SLICK-A Cre; ROSA 26 reporter mice demonstrated clear induction of Cre activity (assessed by $\beta$-galactosidase expression) in YFP-expressing motoneurons and DRG cells after tamoxifen but not vehicle administration in the adult (supplemental Fig. 2, available at www.jneurosci. org as supplemental material). SLICK-A Cre mice were crossed with mice homozygous for the conditional $\mathrm{Nrgl}$ allele $\left(\mathrm{Nrgl}^{\mathrm{f} / f}\right)$, which have loxP sites flanking the sequences encoding the essential EGF domain (Meyer and Birchmeier, 1995; Yang et al., 2001; Li et al., 2002). In SLICK-A Cre; NRG- $1^{f l f f}$ animals, we used in situ hybridization and a probe directed against the $\beta$ isoform of the EGF domain to confirm the absence of EGF-domain mRNA sequences in YFP-labeled sensory and motoneurons after administration of tamoxifen but not vehicle (Fig. 2). After blinded analysis of control animals, 94\% (49 of 52) of YFP-positive motoneurons expressed $\beta \mathrm{EGF}$ domain mRNA, but this was detectable in only $9 \%$ (9 of 98) of YFP-positive motoneurons in SLICK-A Cre; NRG-1 ${ }^{f l f l}$ animals after tamoxifen administration.

To determine whether juxtacrine NRG1 signaling was required for maintenance of the myelin sheath in the naive state, immunoelectron microscopy was used to identify YFP-positive axons within the sciatic nerve of SLICK-A Cre; NRG-1 $1^{f l f l}$ animals. Twelve weeks after tamoxifen or vehicle administration, myelinated fiber morphology was normal (Fig. 3), and there were no significant differences in G-ratio $(0.63 \pm 0.01$ vs $0.62 \pm 0.007$, mean \pm SE, tamoxifen vs vehicle treatment) or axon diameter $(4.7 \pm 0.3$ vs $4.3 \pm 0.34 \mu \mathrm{m}$, tamoxifen vs vehicle). There was no difference in the number of YFP axons in the sciatic nerve of vehicle- or tamoxifen-treated SLICK-A Cre; NRG-1 ${ }^{f l f l}$ mice $(136 \pm 22$ vs $149 \pm 14$, mean $\pm \mathrm{SE}$, tamoxifen vs vehicle). Even at 22 weeks after treatment with tamoxifen, myelinated fiber morphology remained normal (Fig. 3), and there were no significant differences in G-ratio $(0.63 \pm 0.02$ vs $0.6 \pm 0.002$, tamoxifen vs vehicle) or axon diameter ( $5.0 \pm 0.04$ vs $4.9 \pm 0.4 \mu \mathrm{m}$, tamoxifen vs vehicle).
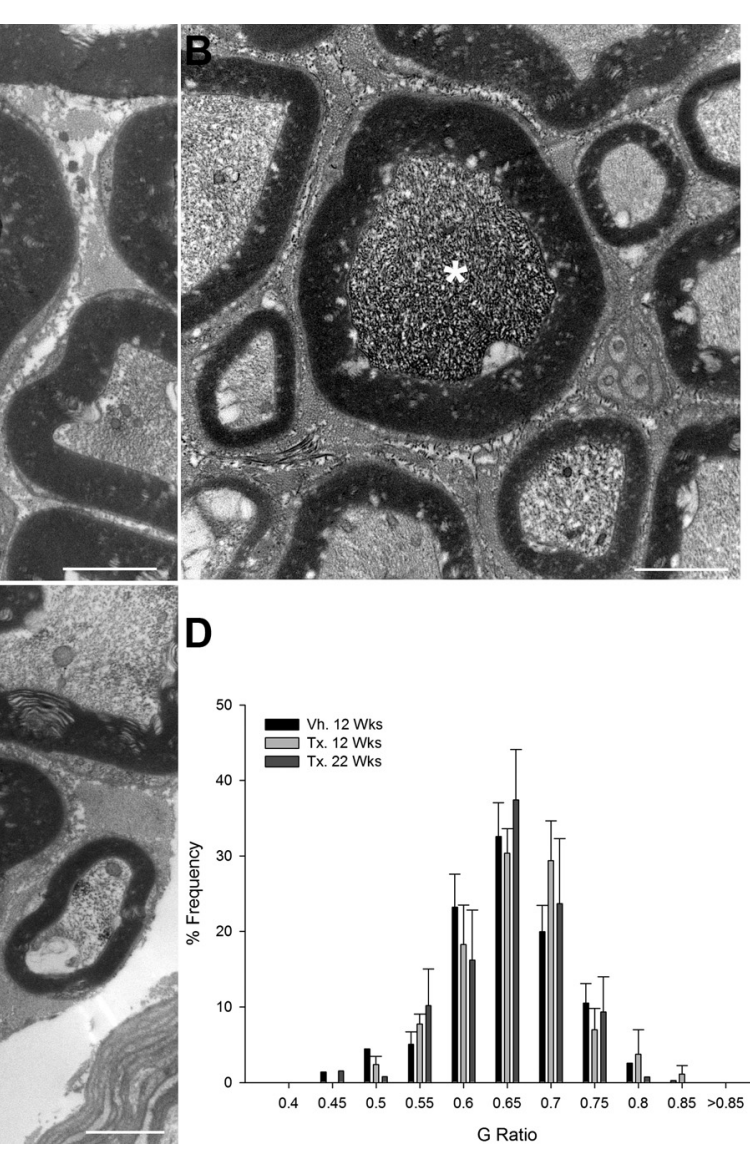

Figure 3. Juxtacrine NRG1 signaling is dispensable for maintenance of the myelin sheath in uninjured adult animals. In SLICK-A animals, YFP-expressing axons can be identified by preembedding immunoelectron microscopy by the presence of a dark reaction weeks after administration of tamoxifen to SLICK-A Cre; NRG- $7^{f l / f l}$ mice compared with control animals (12 weeks after vehicle treatment; $\boldsymbol{A})$. $\boldsymbol{D}, \mathrm{G}$-ratio frequency distribution in nerves of conditional NRG1 mutant and control mice; $n=3-5$ per group. Vh., Vehicle; Tx., tamoxifen. Scale bars, $2 \mu \mathrm{m}$.

\section{NRG1 is essential for remyelination after peripheral nerve injury in adult animals}

To investigate a potential function of NRG1 in axon remyelination and regeneration, we analyzed conditional mutant mice after peripheral nerve injury (Fig. 1). At 8 weeks after sciatic nerve crush, control animals (either vehicle-treated SLICK-A Cre; $N R G-1^{f l / f l}$ or tamoxifen-treated SLICK-A Cre; NRG-1 $1^{+/+}$) showed highly effective remyelination (Fig. 4A) (supplemental Fig. 3, available at www.jneurosci.org as supplemental material). In contrast, YFP-positive axons of conditional NRG1 mutant (tamoxifen-treated SLICK-A Cre; NRG-1 ${ }^{f l f l}$ ) mice demonstrated markedly deficient remyelination: a significant proportion of YFP axons $(38.6 \pm 3.3 \%)$ were ensheathed by Schwann cells but had failed to elaborate a myelin sheath (including axons of up to $5 \mu \mathrm{m}$ in diameter) (Fig. 4C,E). In tamoxifen-treated SLICK-A Cre; NRG- $1^{f l f l}$ animals, the axons that had been remyelinated displayed a significantly thinner myelin sheath, with an average G-ratio of $0.84 \pm 0.02$ (vs $0.72 \pm 0.007$ and $0.68 \pm 0.007$ for vehicle-treated SLICK-A Cre; NRG- $1^{f l / f l}$ and tamoxifen-treated SLICK-A Cre; NRG-1 ${ }^{+/+}$, respectively; $\left.p<0.005\right)($ Fig. $4 B, D)$. In contrast to the marked changes in G-ratio, the axon diameter of regenerated YFP-positive axons was unaffected $(3.78 \pm 0.11$ and $3.63 \pm 0.18 \mu \mathrm{m}$ vehicle- and tamoxifen-treated SLICK-A Cre; $N R G-1^{f l / f l}$, respectively; $n=4$ ).

Additional evidence of deficits in remyelination was apparent when NRG1-deficient YFP-labeled motor axons were visualized 


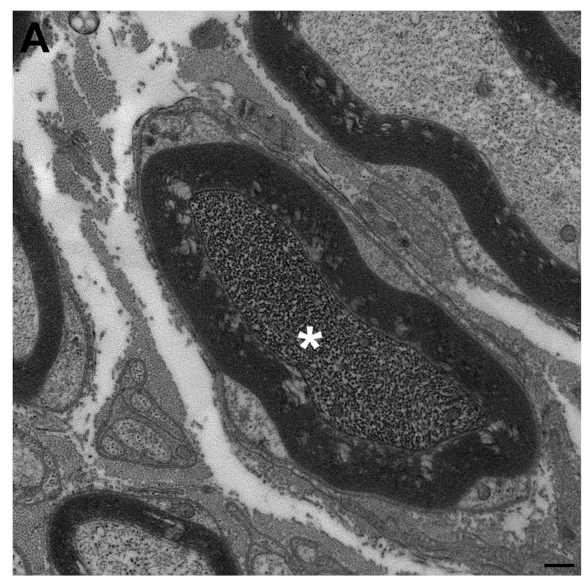

D

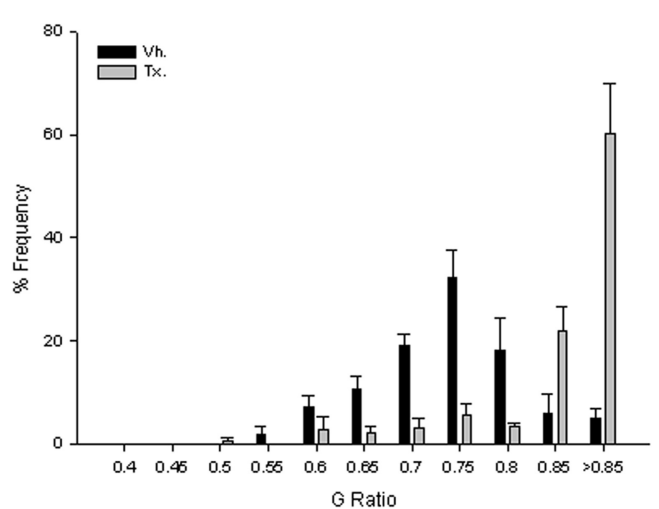

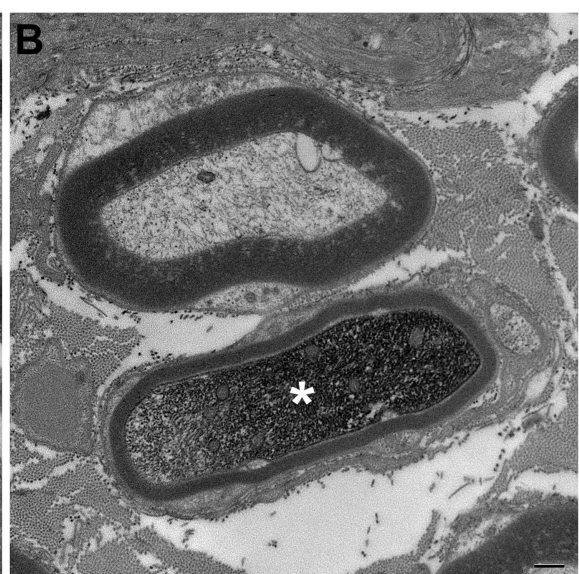

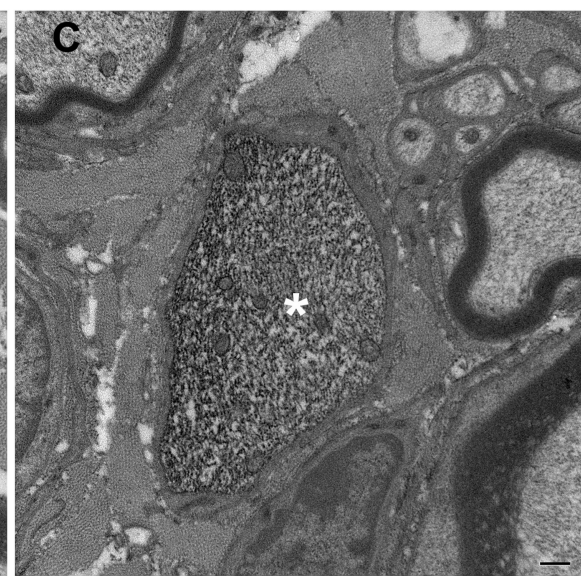

E

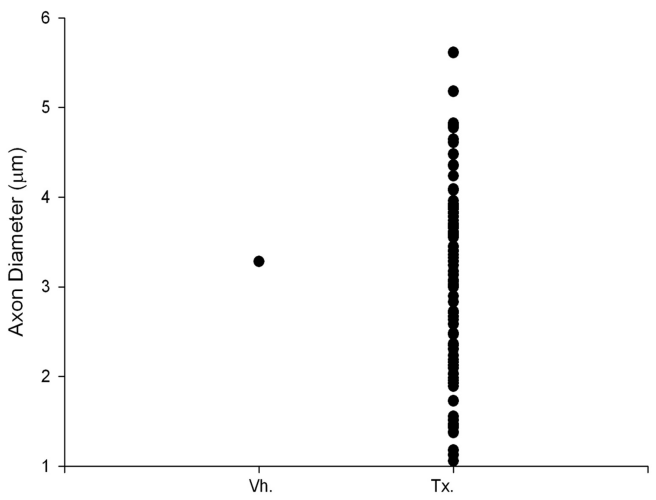

Figure 4. Axon-derived NRG1 is required for remyelination after nerve injury in the adult. $A$, At 8 weeks after sciatic nerve crush, control (vehicle-treated SLICK-A Cre; NRG-7//ff) animals demonstrated effective remyelination of YFP-expressing axons. $\boldsymbol{B}-\boldsymbol{D}$, In contrast, YFP-positive axons from conditional NRG1 mutant (tamoxifen-treated SLICK-A (re; $N R G$ - $7^{f / / f}$ ) mice either had a significantly thinner myelin sheath $(\boldsymbol{B})$ or completely failed to elaborate a myelin sheath ( $\boldsymbol{C}$; quantified in $\boldsymbol{D}, \mathbf{G}$-ratio plot; $p<0.001$, Kolmogorov-Smirnov test). Note in $\boldsymbol{B}$ a neighboring axon that is YFP negative is normally myelinated. $\boldsymbol{E}$, Graphic plot displaying numbers of unmyelinated YFP-positive axons ( $n=4$ animals per group). Vh., Vehicle; Tx., tamoxifen. Scale bar, $500 \mathrm{~nm}$.
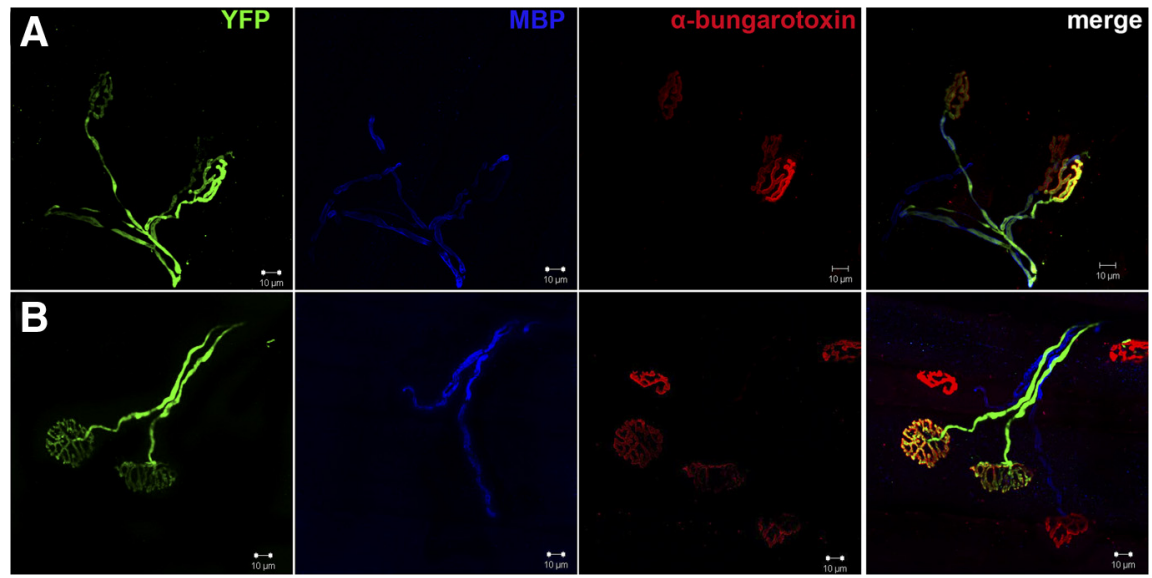

Figure 5. NRG1-deficient axons could be visualized in the gastrocnemius muscle with no myelin sheath 8 weeks after sciatic nerve crush. $\boldsymbol{A}$, In SLICK-A Cre; NRG- $7^{f / / f l}$ animals, regenerated motor axons (YFP, green) at 8 weeks after sciatic nerve crush that have reinnervated an $\alpha$-bungarotoxin (red)-labeled NMJ can be visualized. MBP staining (blue) colocalizes with YFP staining. $\boldsymbol{B}$, NMJ from tamoxifen-treated SLICK-A Cre; NRG- $7^{f / f f l}$ animal (i.e., conditional NRG1 mutant); MBP staining is frequently absent over long lengths from YFP-labeled axons, despite neighboring non-YFP axons staining for MBP. Scale bar, $10 \mu \mathrm{m}$.

within the gastrocnemius muscle. Immunohistological analysis of tamoxifen-treated SLICK-A Cre; NRG-1 $1^{f l f l}$ animals 8 weeks after crush revealed YFP-positive axons along which myelin basic protein (MBP) was absent over long segments, equivalent to the length of multiple internodes (Fig. 5).

\section{NRG1 is required for effective regeneration after peripheral nerve injury in adult animals}

To assess long-range axon regeneration, YFP-labeled axons were visualized in whole-mount preparations of the tibial nerve at $10 \mathrm{~d}, 14 \mathrm{~d}$, or 8 weeks after sciatic nerve crush (Fig. 6). Compared with axons in uninjured tibial nerve, the regenerating axons were thinner and growth cones could be identified (supplemental Fig. 4, available at www.jneurosci.org as supplemental material). At $10 \mathrm{~d}$ after sciatic nerve crush, YFP-positive axons from tamoxifen-treated SLICK-A Cre; NRG$1^{f l f l}$ animals demonstrated a significant reduction in regeneration distance from the crush site compared with control (either vehicle-treated SLICK-A Cre; NRG$1^{f l f l}$ or tamoxifen-treated SLICK-A Cre; $N R G-1^{+/+}$animals; $p<0.05$, two-way ANOVA) (Fig. 6) (supplemental Fig. 4, available at www.jneurosci.org as supplemental material). At $14 \mathrm{~d}$ after crush, although the YFP-positive axons of tamoxifentreated SLICK-A Cre; NRG-1 $1^{f l f l}$ mice had regenerated a farther distance through the tibial nerve, this was still significantly reduced compared with vehicle-treated animals (tamoxifen vs vehicle 
treatment of SLICK-A Cre; NRG-1 ${ }^{f l / f l} ; p<$ 0.05, two-way ANOVA). At 8 weeks after crush, the axons had fully regenerated through the tibial nerve, and no significant difference between the groups was observable (Fig. 6).

\section{NRG1 ablation results in excess terminal sprouting at the neuromuscular junction after} peripheral nerve injury in adult animals We examined the consequences of NRG1 ablation on the NMJ. In the gastrocnemius muscle of SLICK-A mice, $30 \%$ of NMJs are innervated by YFP-positive motoneurons. In SLICK-A Cre; NRG-1 $1^{f l f l}$ mice 12 weeks after tamoxifen administration, the structure of the NMJ was normal (Fig. 7A). The reinnervation of gastrocnemius NMJs was then assessed at $10 \mathrm{~d}, 14 \mathrm{~d}$, and 8 weeks after sciatic nerve crush. At $10 \mathrm{~d}$, the level of NMJ reinnervation was low in both groups and did not significantly differ between them $(1.4 \pm 0.5$ vs $2.5 \pm 0.6 \%$ of gastrocnemius NMJs were innervated by YFP-positive axons at $10 \mathrm{~d}$ after crush in the tamoxifen vs vehicle treatment groups of SLICK-A Cre; NRG-1 $1^{\text {fl/fl }}$ animals; $p=0.2$ ). At $14 \mathrm{~d}$ after crush, NMJ reinnervation was more established; the proportion of NMJs that were reinnervated by YFP-positive axons was not significantly different comparing tamoxifen-treated with vehicle-treated SLICK-A Cre; NRG-1 $1^{f l f l}$ animals $(20.5 \pm 3.2$ vs $18.2 \pm 3.2 \%$ of gastrocnemius NMJs, respectively). However, at this time, a greater proportion of the NRG1deficient axons demonstrated partial rather than full innervation (the proportion of NMJs that were partially innervated by YFP-positive axons was $10.8 \pm 1.25$ vs $6.8 \pm 1.49 \%$ tamoxifentreated vs vehicle-treated SLICK-A Cre; NRG-1 $\left.1^{f l / f l} ; p<0.05\right)$. At 8 weeks after crush, the number of NMJs innervated by YFP-positive axons had returned to the preinjury level in all groups and were fully innervated ( $30.8 \pm 5.5$ vs $22.8 \pm 3.4 \%$ tamoxifen-treated vs vehicletreated SLICK-A Cre; NRG-1 $1^{f l / f l}$; no significant difference). Although in the tamoxifen-treated SLICK-A Cre; NRG-1 $1^{f l / f l}$ group the NMJ was fully reinnervated at this time point, there was a much higher rate of terminal sprouting (Fig. $7 D, E$ ). These sprouts were associated with the processes of terminal Schwann cells as revealed by immunostaining with S100 antibodies.

\section{Discussion}

In this study, we used SLICK mice to ablate NRG1 conditionally in a subset of adult sensory and motoneurons. We have found that axons lacking NRG1 were able to maintain a myelin sheath but were severely impaired in remyelination after nerve injury. Such axons also showed a slower rate of regeneration, and, although they reinnervated their targets, the neuromuscular junction demonstrated excessive terminal sprouting.

The expression of the SLICK transgene in a subpopulation of sensory and motor neurons enabled us to probe the role of juxtacrine NRG1 signaling in the maintenance of the myelin sheath.

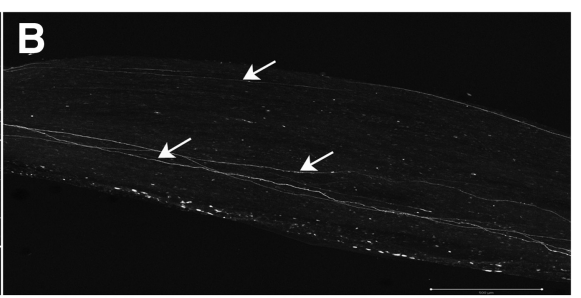

D 140
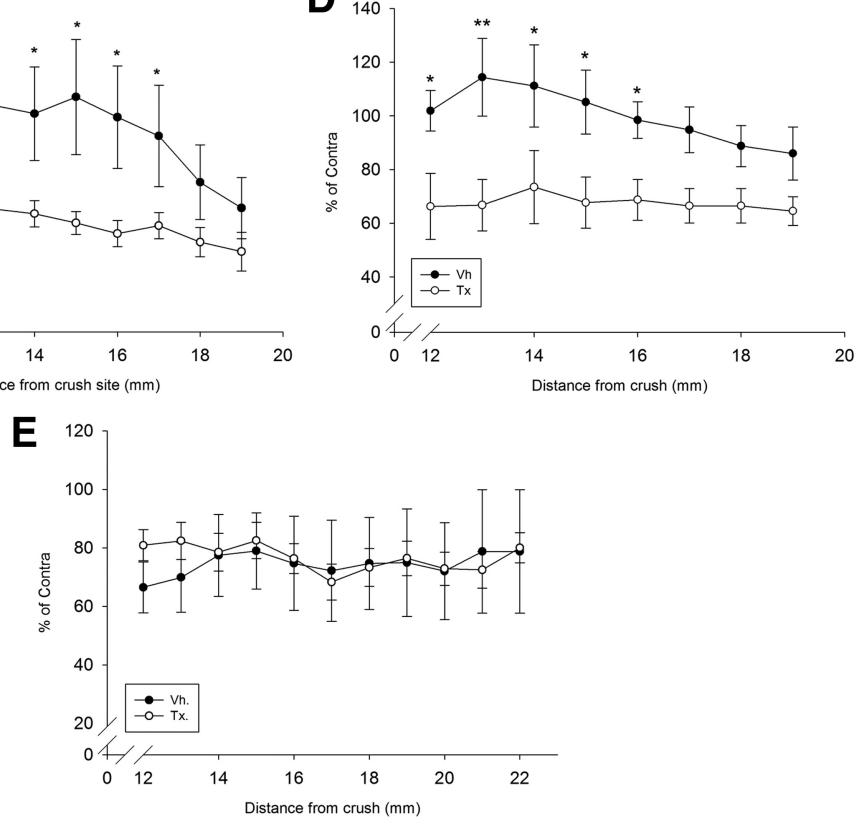

Figure 6. NRG1-deficient axons regenerate at a slower rate. $\boldsymbol{A}, \boldsymbol{B}$, YFP-positive axons (see arrows) within the full thickness of the tibial nerve can be visualized using confocal microscopy $10 \mathrm{~d}$ after sciatic nerve crush in vehicle-treated $(\boldsymbol{A})$ and tamoxifen-treated S 作 versus distance from crush site. There is a significant difference between the tamoxifen- and vehicle-treated group at both 10 (D) days after crush ( $n=7$ per group; ${ }^{*} p<0.05,{ }^{* *} p<0.005$, two-way ANOVA post hoc Tukey's test). $\boldsymbol{E}$, At 2 months after crush, axons had effectively regenerated through the tibial nerve in both groups, with no significant difference between them ( $n=5$ per group). Vh., Vehicle; Tx., tamoxifen. Scale bars, $500 \mu \mathrm{m}$.

There is evidence that a transcriptional program maintains the Schwann cell myelinating phenotype in adulthood. Krox20 is a key transcriptional regulator of myelination during development (Topilko et al., 1994), and conditional ablation of Krox20 in adult Schwann cells results in rapid myelin breakdown accompanied by the expression of genes such as Sox2 associated with Schwann cell dedifferentiation (Le et al., 2005; Decker et al., 2006). The fact that in vitro axon contact promotes Krox20 expression by Schwann cells (Murphy et al., 1996) and that loss of axonal contact in vivo results in downregulation of Krox20 [and other myelin related genes (Zorick et al., 1996)] might suggest that NRG1 is required for continued Krox20 expression and myelin maintenance. We did not find, however, that juxtacrine NRG1 signaling was required for myelin maintenance. At 22 weeks after tamoxifen administration to SLICK-A Cre; NRG-1 $1^{f l / f l}$ animals, YFP axon and myelin morphology remained normal. The exact halflife of the NRG1 protein is unknown, so the actual period of NRG1 deficiency may be less than the full 22 weeks. Because we only ablated NRG1 in a subset of axons, neighboring axons, or even Schwann cells (Rosenbaum et al., 1997) might release Igcontaining NRG1 isoforms, which could signal in a paracrine manner and theoretically compensate for the absent juxtacrine NRG1 signaling in tamoxifen-treated SLICK-A Cre; NRG-1 $1^{f l f l}$ 


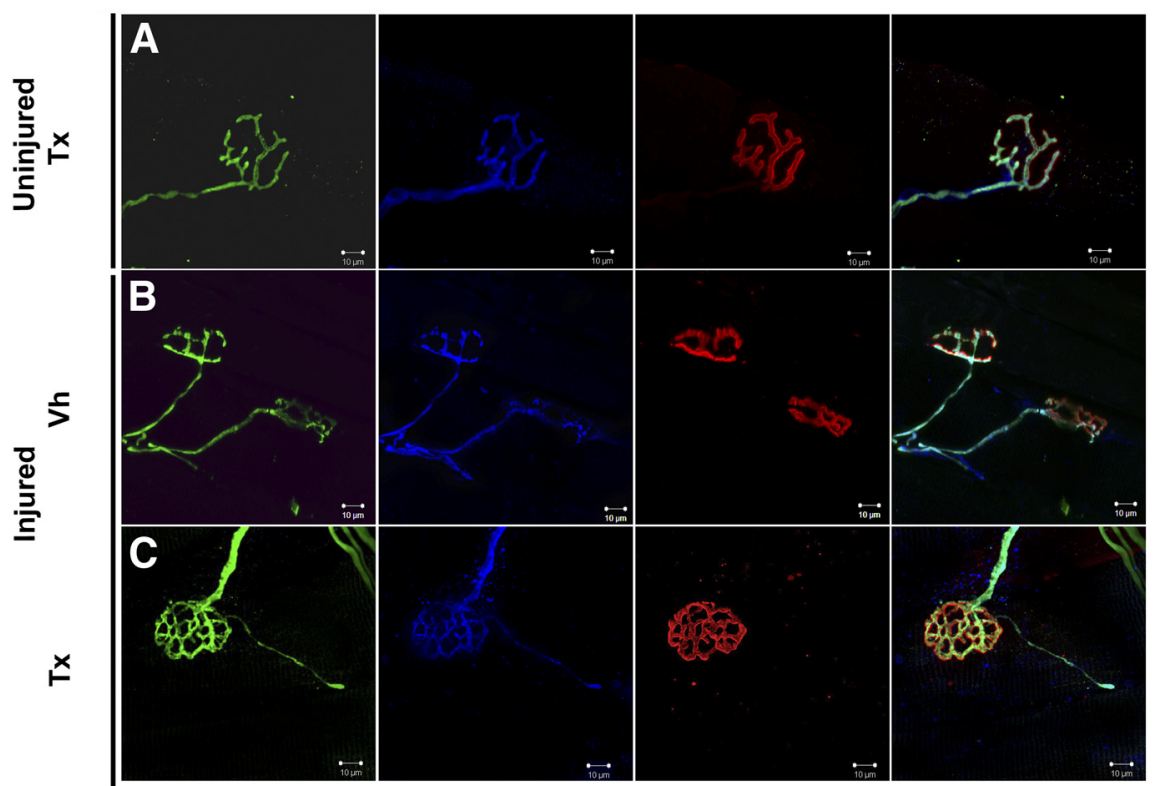

D

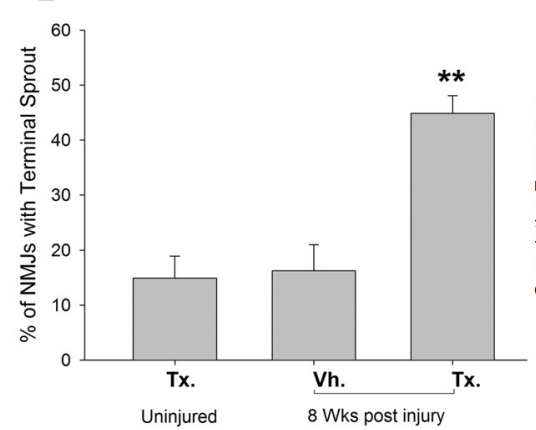

E

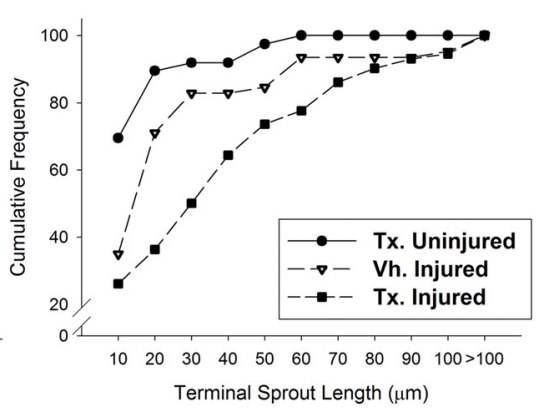

Figure 7. NRG1 ablation results in excess terminal sprouting at the neuromuscular junction after peripheral nerve injury. $\boldsymbol{A}$, The neuromuscular junction 12 weeks after tamoxifen administration to SLICK-A Cre; NRG- $1^{f / f l}$ animals (conditional NRG1 mutant) demonstrated normal apposition and morphology of presynaptic and postsynaptic elements (YFP, green; S100, blue; $\alpha$-bungarotoxin, red, respectively). $\boldsymbol{B}, \boldsymbol{C}$, At 8 weeks after sciatic nerve crush; $\boldsymbol{C}$, NMJs of conditional NRG1 mutant animals were reinnervated but had a much higher degree of terminal sprouting compared with control $(\boldsymbol{B})$. These axonal sprouts clearly followed the processes of terminal Schwann cells immunolabeled by S-100 (blue). $\boldsymbol{D}$, There was a significant increase in the proportion of NMJs with sprouts ( ${ }^{* *} p<0.005$, one-way ANOVA post hoc Tukey's test). $\boldsymbol{E}$, When terminal sprout length is plotted as cumulative sum distributions, sciatic crush results in a small but significant increase in sprout length in vehicle-treated animals $(p<0.005$, Kolmogorov-Smirnov test), but sprout length is significantly greater in tamoxifen-treated animals $(p<0001$, KolmogorovSmirnov test). $n=3$ animals per group. Vh., Vehicle; Tx., tamoxifen. Scale bars, $10 \mu \mathrm{m}$.

animals. Conditional ablation of ErbB2, the receptor that participates in NRG1 signal transduction, in Schwann cells of mature mice does not result in any change in myelinated fiber morphology up to 2 months after tamoxifen administration, supporting the notion that ongoing NRG1-ErbB signaling is not required for myelin maintenance (Atanasoski et al., 2006).

Traumatic nerve injury results in a sequence of cellular changes termed Wallerian degeneration: distal axonal segments degenerate, myelin breaks down, Schwann cells dedifferentiate/ proliferate, and macrophages phagocytose debris (Chen et al., 2007). Subsequently, axons regenerate into bands of Bungner (Schwann cells within tubes of basal lamina), Schwann cells differentiate into a myelinating phenotype (Zorick et al., 1996), axons are remyelinated, and saltatory conduction is reestablished. Of note, remyelinated fibers have a thinner myelin sheath (Schröder, 1972) and shorter internodal distance (Minwegen and Friede, 1985).

Given its key developmental role, we investigated whether NRG1 provides an axoglial signal promoting remyelination. It has been shown previously that nerve injury results in increased expression of the ErbB2 and ErbB3 receptors within Schwann cells of the distal nerve (Cohen et al., 1992; Carroll et al., 1997; Kwon et al., 1997). Changes in the expression of Neuregulin-1 isoforms after injury are complex. Expression of the type III isoform, the isoform responsible for myelination, in sensory and motoneurons decreases initially and then returns to normal levels as axons reinnervate peripheral targets (Bermingham-McDonogh et al., 1997). In contrast, the expression of isoforms containing Ig-like domains increases at the site of injury (Carroll et al., 1997).

We observed at 2 months after sciatic nerve crush that axons lacking NRG1 had significantly thinner myelin sheaths, and $40 \%$ had completely failed to elaborate a myelin sheath despite being ensheathed by Schwann cells. While visualizing motor axons, it was clear that long lengths of NRG1-deficient axons were amyelinated. The type III isoform of NRG1 requires proteolytic cleavage by BACE1 for full activity, and reduced remyelination of axons has also been observed in $B A C E^{-/-}$ mice (Hu et al., 2008). Not all aspects of the Schwann cell response to axon injury are, however, dependent on NRG1-ErbB signaling. In a previous study in which the ErbB2 receptor was conditionally ablated in adult Schwann cells, no effect on Schwann cell proliferation distal to a site of nerve transaction was noted (Atanasoski et al., 2006). Given the small proportions of axons in which we ablated NRG1 in this study, we did not analyze Schwann cell proliferation here.

It is well established that the response of Schwann cells after nerve injury promotes axon regeneration (Chen et al., 2007). This is likely to be mediated through multiple mechanisms, including the expression of neurotrophic factors, extracellular matrix components, and removal of myelin components that are inhibitory to axonal outgrowth. In axons lacking NRG1, axonal regeneration was slowed at 10 and $14 \mathrm{~d}$ after sciatic nerve crush, but at 8 weeks there was no difference from control. Altered interactions with Schwann cells could have a role in the slowed regeneration of NRG1-deficient axons, for instance, a reduction in the synthesis of factors that promote axonal outgrowth. Addition of soluble NRG1 to the culture media promotes axon outgrowth from cultured superior cervical ganglion neurons; this effect is indirect and occurs via the release of growth-promoting agents from Schwann cells in response to NRG1 (Mahanthappa et al., 1996). Impaired myelination per se is unlikely to cause the slowed axon regeneration. In the control animals, myelination had not commenced in the majority of YFP axons in the sciatic nerve at 10 days after crush, a time when there was a clear difference in regeneration of these axons into the tibial nerve (our unpublished observations). NRG1 might promote 
axon outgrowth in a cell-autonomous manner by "back signaling" of transmembrane NRG1 isoforms. ErbB binding to NRG1 has been shown in certain model systems to result in $\gamma$-secretasedependent cleavage, releasing the intracellular domain that is targeted to the nucleus in which it modulates gene transcription (Bao et al., 2003). It was recently reported that axon outgrowth in developing cortical neurons can be modulated by expression of the type III isoform of NRG1, which appeared to be independent of back signaling and was mediated by an as yet unidentified signaling system (Chen et al., 2010).

Recent analysis of mutant mice suggest that NRG1 signaling is dispensable for NMJ formation (Escher et al., 2005; Jaworski and Burden, 2006). We did not observe changes in NMJ structure after NRG1 ablation in adult motoneurons. At 2 weeks after sciatic nerve crush, there was no difference in the total number of NMJs reinnervated by axons lacking NRG1, although a greater number were partially rather than fully reinnervated. The mild phenotype in neuromuscular reinnervation compared with the clear reduction in long-range axon regeneration may correlate with a greater capacity of NRG1-deficient axons to sprout locally once they reach their targets. At 8 weeks after injury, the NMJ was fully reinnervated in all groups, but a much higher level of terminal sprouting was noted in axons lacking NRG1. Terminal sprouting is a phenomenon that is triggered by denervation or inhibition of synaptic transmission (e.g., from botulinum toxin) at the NMJ (Kang et al., 2003). We found, as others have described previously, that such terminal sprouts follow terminal Schwann cell processes (Son and Thompson, 1995). These specialized nonmyelinating Schwann cells cap the NMJ and have been shown to respond to NRG1-ErbB signaling. Treatment with exogenous NRG1 rescues terminal Schwann cells from apoptosis after neonatal axotomy (Trachtenberg and Thompson, 1996), and expression of constitutively active ErbB2 in Schwann cells results in proliferation and process extension from these cells (Hayworth et al., 2006). Our findings suggest that axonally derived NRG1 is clearly dispensable for terminal Schwann cell process extension. The excess terminal sprouting that we observed may not be a direct consequence of the absence of NRG1 at the NMJ itself but instead secondary to the grossly impaired remyelination of the motor axons. Increased NMJ terminal sprouting has been described previously in a mutant mouse model of a demyelinating neuropathy, EGR2 I268N, as a consequence of conduction block (Baloh et al., 2009).

In conclusion, during adulthood, NRG1 has a key role in mediating the signaling between axons and Schwann cells required for effective nerve repair. Our data indicate that therapeutics based on the inhibition of ErbB signaling in oncology (Lurje and Lenz, 2009) and BACE1 in Alzheimer's disease (Vassar et al., 2009) will not impair normal nerves but will significantly interfere with the regenerative response to nerve injury.

\section{References}

Atanasoski S, Scherer SS, Sirkowski E, Leone D, Garratt AN, Birchmeier C, Suter U (2006) ErbB2 signaling in Schwann cells is mostly dispensable for maintenance of myelinated peripheral nerves and proliferation of adult Schwann cells after injury. J Neurosci 26:2124-2131.

Baloh RH, Strickland A, Ryu E, Le N, Fahrner T, Yang M, Nagarajan R, Milbrandt J (2009) Congenital hypomyelinating neuropathy with lethal conduction failure in mice carrying the Egr2 I268N mutation. J Neurosci 29:2312-2321.

Bao J, Wolpowitz D, Role LW, Talmage DA (2003) Back signaling by the Nrg-1 intracellular domain. J Cell Biol 161:1133-1141.

Bermingham-McDonogh O, Xu YT, Marchionni MA, Scherer SS (1997) Neuregulin expression in PNS neurons: isoforms and regulation by target interactions. Mol Cell Neurosci 10:184-195.
Brinkmann BG, Agarwal A, Sereda MW, Garratt AN, Müller T, Wende H, Stassart RM, Nawaz S, Humml C, Velanac V, Radyushkin K, Goebbels S, Fischer TM, Franklin RJ, Lai C, Ehrenreich H, Birchmeier C, Schwab MH, Nave KA (2008) Neuregulin-1/ErbB signaling serves distinct functions in myelination of the peripheral and central nervous system. Neuron 59:581-595.

Carroll SL, Miller ML, Frohnert PW, Kim SS, Corbett JA (1997) Expression of neuregulins and their putative receptors, ErbB2 and ErbB3, is induced during Wallerian degeneration. J Neurosci 17:1642-1659.

Chen S, Rio C, Ji RR, Dikkes P, Coggeshall RE, Woolf CJ, Corfas G (2003) Disruption of ErbB receptor signaling in adult non-myelinating Schwann cells causes progressive sensory loss. Nat Neurosci 6:1186-1193.

Chen Y, Hancock ML, Role LW, Talmage DA (2010) Intramembranous valine linked to schizophrenia is required for neuregulin 1 regulation of the morphological development of cortical neurons. J Neurosci 30:9199-9208.

Chen ZL, Yu WM, Strickland S (2007) Peripheral regeneration. Annu Rev Neurosci 30:209-233.

Cohen JA, Yachnis AT, Arai M, Davis JG, Scherer SS (1992) Expression of the neu proto-oncogene by Schwann cells during peripheral nerve development and Wallerian degeneration. J Neurosci Res 31:622-634.

Decker L, Desmarquet-Trin-Dinh C, Taillebourg E, Ghislain J, Vallat JM, Charnay P (2006) Peripheral myelin maintenance is a dynamic process requiring constant Krox20 expression. J Neurosci 26:9771-9779.

Escher P, Lacazette E, Courtet M, Blindenbacher A, Landmann L, Bezakova G, Lloyd KC, Mueller U, Brenner HR (2005) Synapses form in skeletal muscles lacking neuregulin receptors. Science 308:1920-1923.

Falls DL (2003) Neuregulins: functions, forms, and signaling strategies. Exp Cell Res 284:14-30.

Falls DL, Rosen KM, Corfas G, Lane WS, Fischbach GD (1993) ARIA, a protein that stimulates acetylcholine receptor synthesis, is a member of the neu ligand family. Cell 72:801-815.

Fricker FR, Zhu N, Tsantoulas C, Abrahamsen B, Nassar MA, Thakur M, Garratt AN, Birchmeier C, McMahon SB, Wood JN, Bennett DL (2009) Sensory axon-derived neuregulin-1 is required for axoglial signaling and normal sensory function but not for long-term axon maintenance. J Neurosci 29:7667-7678

Garratt AN, Britsch S, Birchmeier C (2000) Neuregulin, a factor with many functions in the life of a schwann cell. Bioessays 22:987-996.

Hayworth CR, Moody SE, Chodosh LA, Krieg P, Rimer M, Thompson WJ (2006) Induction of neuregulin signaling in mouse Schwann cells in vivo mimics responses to denervation. J Neurosci 26:6873-6884.

Hu X, Hicks CW, He W, Wong P, Macklin WB, Trapp BD, Yan R (2006) Bacel modulates myelination in the central and peripheral nervous system. Nat Neurosci 9:1520-1525.

Hu X, He W, Diaconu C, Tang X, Kidd GJ, Macklin WB, Trapp BD, Yan R (2008) Genetic deletion of BACE1 in mice affects remyelination of sciatic nerves. FASEB J 22:2970-2980.

Jaworski A, Burden SJ (2006) Neuromuscular synapse formation in mice lacking motor neuron- and skeletal muscle-derived Neuregulin-1. J Neurosci 26:655-661.

Kang H, Tian L, Thompson W (2003) Terminal Schwann cells guide the reinnervation of muscle after nerve injury. J Neurocytol 32:975-985.

Kwon YK, Bhattacharyya A, Alberta JA, Giannobile WV, Cheon K, Stiles CD, Pomeroy SL (1997) Activation of ErbB2 during wallerian degeneration of sciatic nerve. J Neurosci 17:8293-8299.

Le N, Nagarajan R, Wang JY, Araki T, Schmidt RE, Milbrandt J (2005) Analysis of congenital hypomyelinating Egr2Lo/Lo nerves identifies Sox2 as an inhibitor of Schwann cell differentiation and myelination. Proc Natl Acad Sci U S A 102:2596-2601.

Li L, Cleary S, Mandarano MA, Long W, Birchmeier C, Jones FE (2002) The breast proto-oncogene, HRGalpha regulates epithelial proliferation and lobuloalveolar development in the mouse mammary gland. Oncogene 21:4900-4907.

Lurje G, Lenz HJ (2009) EGFR signaling and drug discovery. Oncology 77:400-410.

Mahanthappa NK, Anton ES, Matthew WD (1996) Glial growth factor 2, a soluble neuregulin, directly increases Schwann cell motility and indirectly promotes neurite outgrowth. J Neurosci 16:4673-4683.

Mei L, Xiong WC (2008) Neuregulin 1 in neural development, synaptic plasticity and schizophrenia. Nat Rev Neurosci 9:437-452.

Meyer D, Birchmeier C (1995) Multiple essential functions of neuregulin in development. Nature 378:386-390. 
Meyer D, Yamaai T, Garratt A, Riethmacher-Sonnenberg E, Kane D, Theill LE, Birchmeier C (1997) Isoform-specific expression and function of neuregulin. Development 124:3575-3586.

Michailov GV, Sereda MW, Brinkmann BG, Fischer TM, Haug B, Birchmeier C, Role L, Lai C, Schwab MH, Nave KA (2004) Axonal neuregulin-1 regulates myelin sheath thickness. Science 304:700-703.

Minwegen P, Friede RL (1985) A correlative study of internode proportions and sensitivity to procaine in regenerated frog sciatic nerves. Exp Neurol $87: 147-164$

Morris JK, Lin W, Hauser C, Marchuk Y, Getman D, Lee KF (1999) Rescue of the cardiac defect in ErbB2 mutant mice reveals essential roles of ErbB2 in peripheral nervous system development. Neuron 23:273-283.

Murphy P, Topilko P, Schneider-Maunoury S, Seitanidou T, Baron-Van Evercooren A, Charnay P (1996) The regulation of Krox-20 expression reveals important steps in the control of peripheral glial cell development. Development 122:2847-2857.

Riethmacher D, Sonnenberg-Riethmacher E, Brinkmann V, Yamaai T, Lewin GR, Birchmeier C (1997) Severe neuropathies in mice with targeted mutations in the ErbB3 receptor. Nature 389:725-730.

Rosenbaum C, Karyala S, Marchionni MA, Kim HA, Krasnoselsky AL, Happel B, Isaacs I, Brackenbury R, Ratner N (1997) Schwann cells express NDF and SMDF/n-ARIA mRNAs, secrete neuregulin, and show constitutive activation of erbB3 receptors: evidence for a neuregulin autocrine loop. Exp Neurol 148:604-615.

Schröder JM (1972) Altered ratio between axon diameter and myelin sheath thickness in regenerated nerve fibers. Brain Res 45:49-65.

Son YJ, Thompson WJ (1995) Nerve sprouting in muscle is induced and guided by processes extended by Schwann cells. Neuron 14:133-141.

Taveggia C, Zanazzi G, Petrylak A, Yano H, Rosenbluth J, Einheber S, Xu X,
Esper RM, Loeb JA, Shrager P, Chao MV, Falls DL, Role L, Salzer JL (2005) Neuregulin-1 type III determines the ensheathment fate of axons. Neuron 47:681-694.

Topilko P, Schneider-Maunoury S, Levi G, Baron-Van Evercooren A, Chennoufi AB, Seitanidou T, Babinet C, Charnay P (1994) Krox-20 controls myelination in the peripheral nervous system. Nature 371:796-799.

Trachtenberg JT, Thompson WJ (1996) Schwann cell apoptosis at developing neuromuscular junctions is regulated by glial growth factor. Nature 379:174-177.

Vassar R, Kovacs DM, Yan R, Wong PC (2009) The beta-secretase enzyme BACE in health and Alzheimer's disease: regulation, cell biology, function, and therapeutic potential. J Neurosci 29:12787-12794.

Willem M, Garratt AN, Novak B, Citron M, Kaufmann S, Rittger A, DeStrooper B, Saftig P, Birchmeier C, Haass C (2006) Control of peripheral nerve myelination by the beta-secretase BACE1. Science 314: $664-666$.

Woldeyesus MT, Britsch S, Riethmacher D, Xu L, Sonnenberg-Riethmacher E, Abou-Rebyeh F, Harvey R, Caroni P, Birchmeier C (1999) Peripheral nervous system defects in erbB2 mutants following genetic rescue of heart development. Genes Dev 13:2538-2548.

Yang X, Arber S, William C, Li L, Tanabe Y, Jessell TM, Birchmeier C, Burden SJ (2001) Patterning of muscle acetylcholine receptor gene expression in the absence of motor innervation. Neuron 30:399-410.

Young P, Qiu L, Wang D, Zhao S, Gross J, Feng G (2008) Single-neuron labeling with inducible Cre-mediated knockout in transgenic mice. Nat Neurosci 11:721-728.

Zorick TS, Syroid DE, Arroyo E, Scherer SS, Lemke G (1996) The transcription factors SCIP and Krox-20 mark distinct stages and cell fates in Schwann cell differentiation. Mol Cell Neurosci 8:129-145. 